\title{
Analysis of bronchial reactivity in epidemiological studies
}

\author{
Michael J Abramson, Nicholas A Saunders, Michael J Hensley
}

\begin{abstract}
The measurement of bronchial reactivity in epidemiological studies has the advantage of quantifying an objective physiological feature of asthma. Bronchial reactivity was developed in a clinical setting and has been conventionally expressed as the dose of agonist producing a $20 \%$ fall in $F_{E V}\left(\mathbf{P D}_{20}\right)$. As $\mathbf{P D}_{20}$ can be estimated for less than $20 \%$ of subjects in general community surveys with the doses of agonist that are usually given, data from most subjects must be censored. Thus $\mathbf{P D}_{20}$ alone is a poor index of bronchial reactivity for epidemiological studies. Data from 809 aluminium smelter workers were used to evaluate alternative methods of analysing bronchial reactivity. Dose-response relationships were analysed by four methods: (1) $\mathbf{P D}_{20}$ by the conventional method of interpolating the dose on a logarithmic scale between the last two measurements of $F E V_{1}$; (2) $P_{20}$ (with allowance for extrapolation), estimated by fitting an exponential curve to the dose-response data; ( 3 ) the linear regression slope between dose and $F E V_{1}$ when significant; (4) the dose-response slope obtained in all subjects as the \% change in FEV , from baseline in response to total dose. When each of these measures was related to symptoms, diagnosis, and treatment of asthma, all differentiated between "asthmatic" and "non-asthmatic" subjects. The dose-response slope (method 4) had the advantages of simplicity and no censored data, and was shown to be clinically relevant. It is suggested that the dose-response slope should be used for the analysis of bronchial reactivity in epidemiological studies.
\end{abstract}

Bronchial reactivity or responsiveness is both an important physiological outcome and a quantifiable feature of asthma. Epidemiological studies have investigated its distribution in general community surveys conducted in Australia, ${ }^{1-3}$ New Zealand, 5 Papua New Guinea, ${ }^{6}$ the United Kingdom, ${ }^{78}$ and many other countries. For the laboratory diagnosis of asthma bronchial reactivity has conventionally been expressed as the dose of agonist producing a $20 \%$ fall in $\mathrm{FEV}_{1}\left(\mathbf{P D}_{20}\right)$. Most healthy subjects, however, do not show a $20 \%$ fall in $\mathrm{FEV}_{1}$ even with high doses of agonist.
Because $\mathrm{PD}_{20}$ can be estimated in only a minority of subjects in community surveys, it is not an ideal measure of bronchial reactivity for epidemiological research. To describe the distribution of bronchial reactivity in a healthy population completely requires a continuously distributed index that summarises the dose-response data for all individuals.

The slope of the dose-response line has been investigated in laboratory studies as an alternative index of bronchial reactivity. ${ }^{9-11}$ These studies have all included substantial numbers of asthmatic subjects, however, and have not considered the value of slope coefficients in epidemiological studies. Empirical evidence $^{912}$ favours the use of a linear rather than a logarithmic dose scale. In the present study of aluminium workers two methods for deriving $\mathbf{P D}_{20}$ were compared and alternative indices of bronchial reactivity evaluated.

\section{Methods}

The subjects were participants in a longitudinal study of respiratory symptoms and lung function in aluminium smelter workers. After giving informed consent, 809 (96\%) of the 843 male employees completed a methacholine challenge, in which they inhaled increasing doses up to $6.14 \mu \mathrm{mol}$ from hand held glass nebulisers according to a rapid method protocol. ${ }^{13} \mathrm{FEV}_{1}$ was measured from maximal flow-volume loops performed to American Thoracic Society standards ${ }^{14}$ on a water sealed spirometer interfaced with a microcomputer (Gould 2400 system). All subjects wore nose clips and were tested in the sitting position. The test was stopped when $\mathrm{FEV}_{1}$ had fallen by $20 \%$ or the highest dose of histamine had been given. Twelve subjects were not challenged because of impaired baseline lung function $\left(\mathrm{FEV}_{1}\right.$ below $65 \%$ predicted for age and height); 22 declined to participate. No appreciable side effects were experienced; one subject complained of flushing and a few developed symptoms of hyperventilation. Salbutamol $5 \mathrm{mg}$ was administered by nebuliser when FEV ${ }_{1}$ fell by $10 \%$ or more, and bronchoconstriction was reversed promptly in all cases. For assessment of reproducibility $727(90 \%)$ of the workers were rechallenged 12 months later, the same protocol being used.

Dose-response relationships were analysed by four methods:

$1 \mathrm{PD}_{20}$ was estimated by the conventional method of interpolating between the last two 


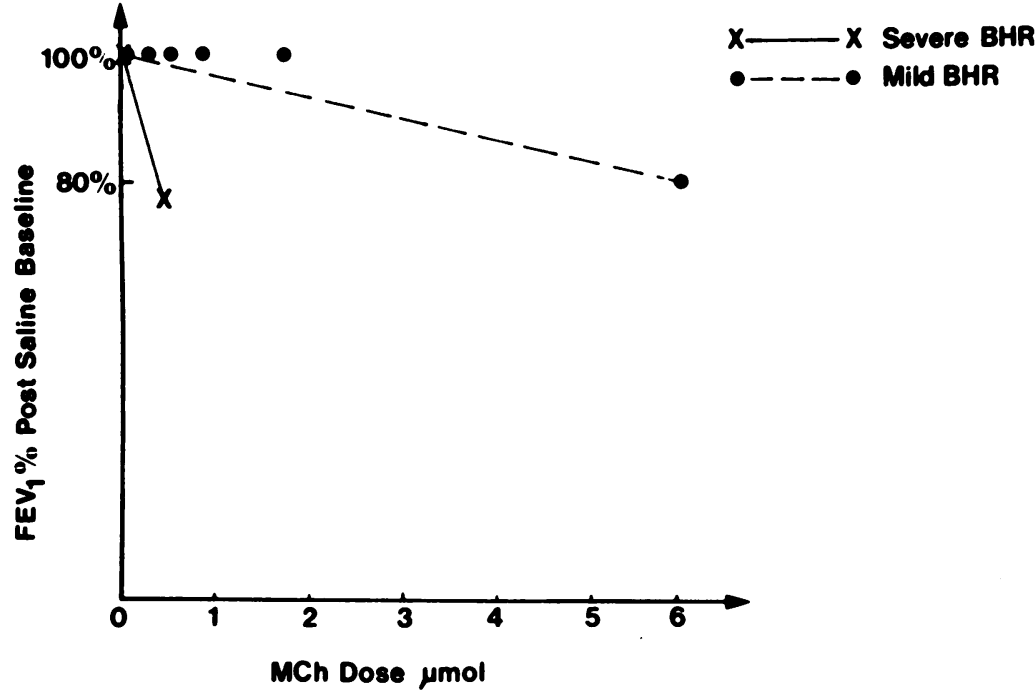

Figure 1 Dose-response slope (DRS) representing a line joining the baseline with

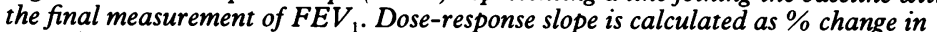
$F E V_{1} /$ total dose methacholine $(\mu \mathrm{mol})$.

measurements on an $\mathrm{FEV}_{1}$-log dose methacholine plot. ${ }^{15}$

2 A Fortran program ${ }^{16}$ was used to fit the exponential function $\mathrm{FEV}_{1}=c-\exp$ $(a+b \star \log$ dose $(\mu \mathrm{mol}$ methacholine $))$. The parameter $c$ was initially set to post-saline $\mathrm{FEV}_{1}$. Ordinary least squares regression was used to estimate the parameters $a$ and $b$. A new value of $c$ was calculated to minimise the residual sum of squares and the regression repeated. Iteration continued until convergence was achieved or the procedure had been performed 50 times. If the algorithm converged, an "exponential" estimate of $\mathrm{PD}_{20}$ was extrapolated up to $12.28 \mu \mathrm{mol}$. Otherwise

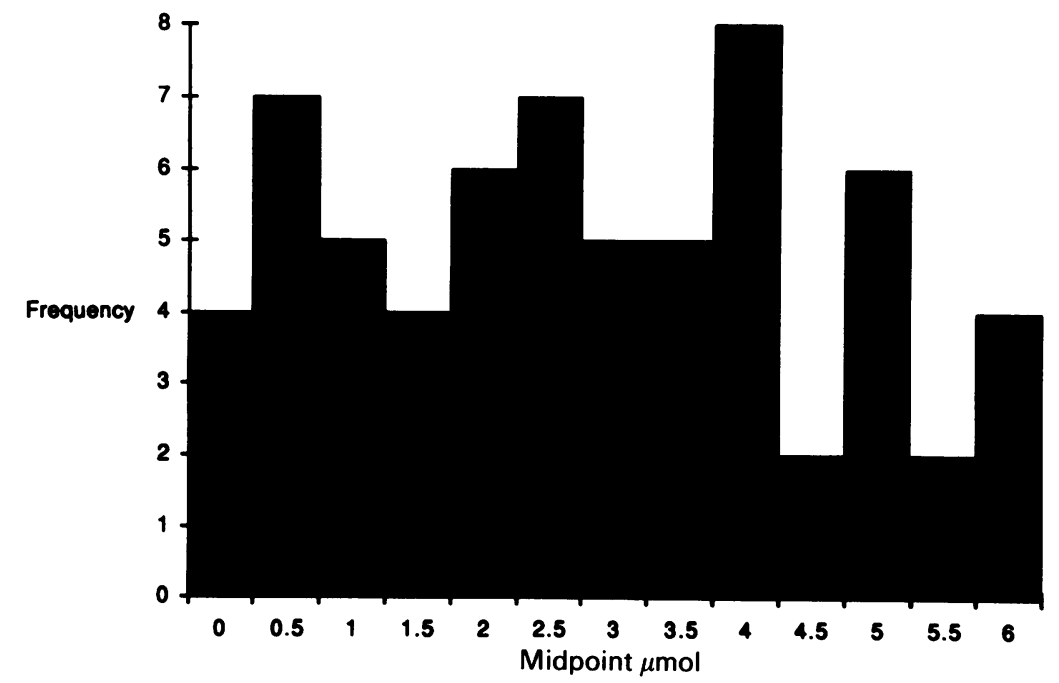

Figure 2 Distribution of $P D_{20}$ interpolated in the usual manner between the last two measurements of FEV, on a log dose scale $(n=65)$. "exponential" $\mathrm{PD}_{20}$ was censored at $12 \cdot 28 \mu \mathrm{mol}$.

3 Ordinary least squares regressions were performed on the data for each subject to fit the dose-response line: $\mathrm{FEV}_{1}=a+b$ dose methacholine $(\mu \mathrm{mol})$. Given a significant linear relationship ( $\mathrm{p}<0.05$ ), the slope parameter $(b)$ was considered as an index of bronchial reactivity. This parameter showed a severely skewed distribution. As the negative reciprocal of slope $(-1 / b)$ was still skewed to the right other power and log transformations of this coefficient were explored in an effort to find the most normally distributed index.

4 The dose-response slope was calculated for each subject as \% decline in FEV, from postsaline value/cumulative methacholine dose. ${ }^{11}$ This parameter represented a line joining the origin of the the dose-response curve with the final measurement (fig 1). Before it was expressed on a logarithmic scale $1.5 \% / \mu \mathrm{mol}$ was added to eliminate negative and zero values.

Descriptive statistics, transformations, correlations, analyses of variance, linear regressions, and associated diagnostics were performed in Minitab. ${ }^{17}$ The correlation of a variable with normal scores for all subjects was used to estimate the Shapiro Wilk coefficient. ${ }^{17}$ The closer the correlation was to unity the more normal the distribution; the significance of deviations from unity was tested. Correlation between continuous indices was assessed by the Pearson's product-moment correlation coefficient. ${ }^{18}$ Reproducibility of indices was assessed by the intraclass correlation coefficient. ${ }^{19}$

Clinical information on any history of asthma, symptoms such as wheeze, and use of bronchodilator medication was obtained from a modified Medical Research Council questionnaire, ${ }^{20}$ completed by all subjects before lung function testing. Differences in two means were assessed by Student's $t$ test and differences in three or more means by analysis of variance. ${ }^{21}$ Separation of symptom groups was assessed by the index $\mathrm{D} / \mathrm{s}$, which was the difference between means divided by the standard deviation for the entire sample. ${ }^{22}$

\section{Results}

ESTIMATES OF PD $_{20}$

After the administration of $6 \cdot 14 \mu \mathrm{mol}$ methacholine $\mathrm{FEV}_{1}$ increased from baseline in 123 $(15 \%)$ subjects, showed no change in $21(3 \%)$, a decrease of less than $10 \%$ in $509(63 \%)$, and a decrease of $10-20 \%$ in $91(11 \%)$ subjects. Only $65(8 \%)$ subjects had a decline in FEV of more $_{1}$ than $20 \%$. For these 65 cases $\mathrm{PD}_{20}$ was inter-

Table 1 Descriptive statistics and tests of normality for different indices of bronchial reactivity $\left(P D_{20}\right)^{\star}$

\begin{tabular}{|c|c|c|c|c|c|c|}
\hline Estimate & $n$ & $\operatorname{Mean}(S D)$ & Minimum & Maximum & $\begin{array}{l}\text { Shapiro-Wilk } \\
\text { coefficient }\end{array}$ & $p$ \\
\hline $\begin{array}{l}\text { Interpolated } \mathrm{PD}_{20} \\
\text { Exponential } \mathrm{PD}_{20} \\
\text { Inverse cube root of slope } \\
\text { Log dose-response slope }\end{array}$ & $\begin{array}{r}65 \\
132 \\
353 \\
809\end{array}$ & $\begin{array}{ll}2 \cdot 8 & (1 \cdot 7) \\
5 \cdot 6 & (3 \cdot 4) \\
2.69 & (0.83) \\
0.36 & (0.29)\end{array}$ & $\begin{array}{r}0.06 \\
0.10 \\
0.54 \\
-0.73\end{array}$ & $\begin{array}{c}6 \cdot 0 \\
12 \cdot 1 \\
5 \cdot 21 \\
2 \cdot 48\end{array}$ & $\begin{array}{l}0.984 \\
0.981 \\
0.997 \\
0.902\end{array}$ & $\begin{array}{c}\text { NS } \\
<0.05 \\
\text { NS } \\
<0.01\end{array}$ \\
\hline
\end{tabular}

*See under "Methods" for derivation of the parameters. 


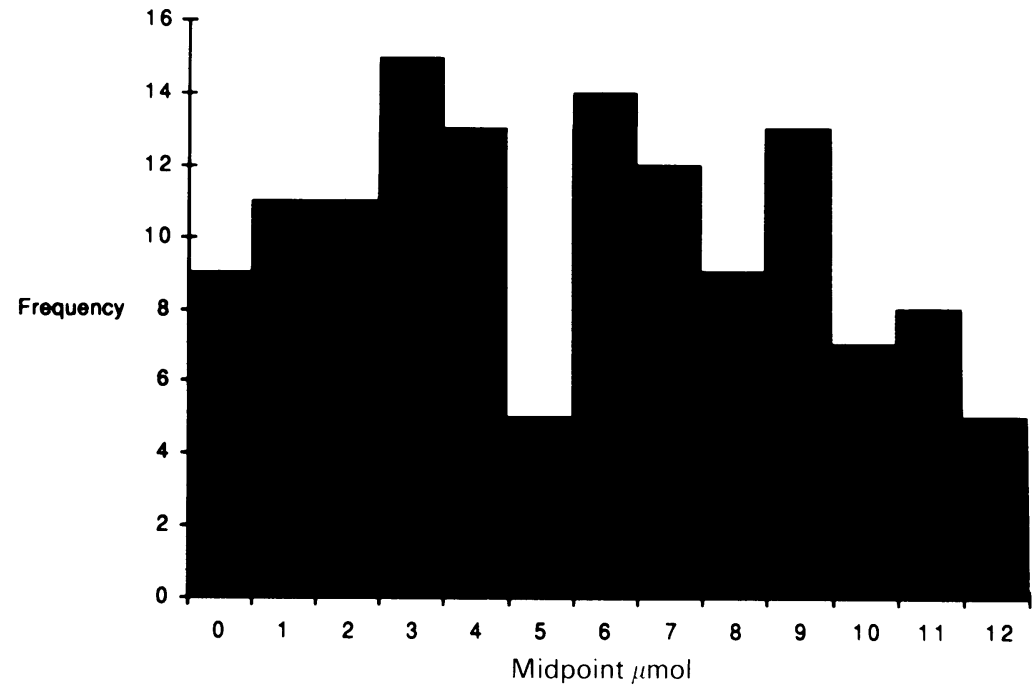

Figure 3 Distribution of $P D_{20}$ extrapolated up to $12 \cdot 28 \mu$ mol by an exponential algorithm-see text $(n=132)$.

polated (see table 1 for descriptive statistics). The distribution of the interpolated $\mathrm{PD}_{20}$ (fig 2) did not deviate significantly from a normal distribution.

The exponential function (method 2) successfully extrapolated a $\mathrm{PD}_{20}$ value for 132 $(16 \%)$ subjects (see table 1 for descriptive statistics). The distribution of this estimate of $\mathrm{PD}_{20}$ (fig 3) deviated significantly from a normal distribution. This deviation was worsened by $\log$ transformation (Shapiro-Wilk coefficient $=0.926)$. One subject's value was censored for being too reactive (a greater than $20 \%$ drop after the first dose) and 676 "nonreactive" subjects were given the censored value $12 \cdot 28 \mu \mathrm{mol}$.

Complete data for interpolated and exponential estimates of $\mathrm{PD}_{20}$ were available for 63 cases. The correlation between the two estimates was $0.94(\mathrm{p}<0.0001)$.

\section{SLOPE PARAMETERS}

The slope of the line of best fit between FEV and methacholine dose on a linear scale (method 3) provided an index of bronchial reactivity for a much larger proportion of subjects. Linear regressions of $\mathrm{FEV}_{1}$ against dose yielded a slope coefficient $(b)$ that was

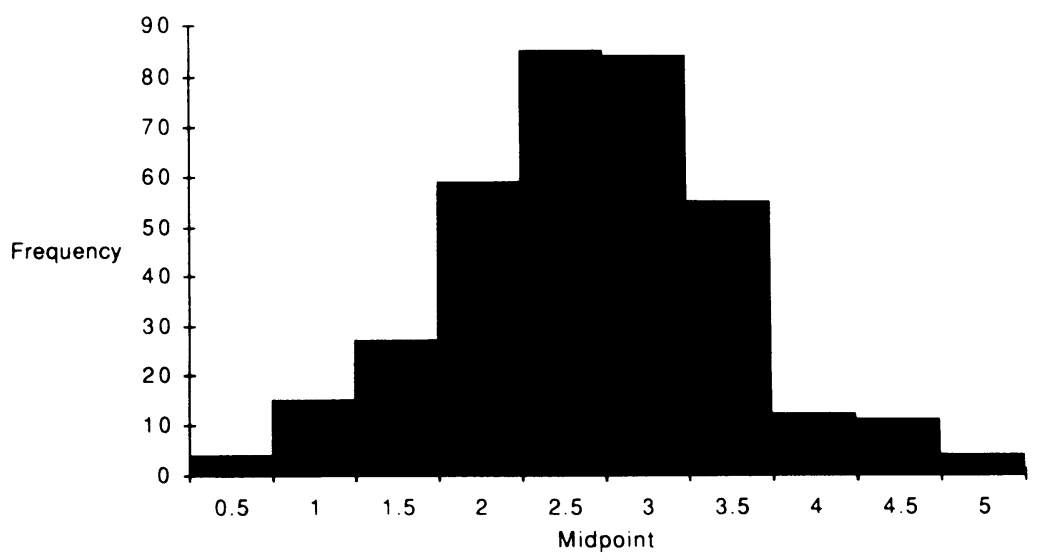

Figure 4 Distribution of the inverse cube root of the slope from significant dose-response lines by linear regression $(n=353)$. The quantities are dimensionless. significantly negative in $353(44 \%)$ of cases. The most normally distributed transformation proved to be the inverse cube root of the slope $\left(b^{-4}\right)$ (fig 4). The descriptive statistics and normality tests for this index are summarised in table 1.

A dose-response slope could be estimated for all 809 subjects. The distribution of the doseresponse slope was severely skewed with two outlying values from extremely reactive individuals. Log transformation yielded a symmetric though significantly non-normally distributed index (fig 5). Descriptive statistics and normality tests for the log dose-response slope are summarised in table 1 .

\section{RELATIONSHIPS BETWEEN PD 20 AND SLOPE} PARAMETERS

There was substantial agreement between the ability to obtain a $\mathrm{PD}_{20}$ from the exponential algorithm (method 2) and the presence of a significant negative slope $(b)$ to the dose response line (method 3)-see table 2. Subjects with an exponential $\mathrm{PD}_{20}$ below $12.28 \mu \mathrm{mol}$ are almost entirely within the group with a significant slope. Iterative exponential curve fitting provided an index of bronchial reactivity in six further cases where simple linear regression failed. The mean inverse cube root of the slope of the 126 subjects with both a significant slope and a $\mathrm{PD}_{20}$ below $12 \cdot 28 \mu \mathrm{mol}$ was significantly less than the mean inverse cube root of the slope for the 227 subjects with a $\mathrm{PD}_{20}$ censored to $12 \cdot 28 \mu \mathrm{mol}$ (table 3 ). In other words, subjects with an extrapolated exponential $\mathrm{PD}_{20}$ have a steeper dose-response line than those without a $\mathrm{PD}_{20}$ value. The correlation between the inverse cube root of the slope and $\mathrm{PD}_{20}$ was very strong $(\mathrm{r}=0.96, \mathrm{p}<0.0001)$.

As the dose-response slope is a summary measure of the slope of the the dose-response line, it is not surprising that there is an extremely strong correlation between this measurement and the slope parameter $(b)$ derived from linear regression $(r=-0.97$, $p<0.0001)$. The strong negative correlation between $\log$ dose-response slope and $\log \mathrm{PD}_{20}$ $(r=-0.98, p<0.0001)$. The mean log doseresponse slope for the 132 subjects with an exponential $\mathrm{PD}_{20}$ below $12 \cdot 28 \mu \mathrm{mol}$ was significantly greater than the mean log dose-response slope for the 227 subjects with a significant negative slope but without a $\mathrm{PD}_{20}$, and this in turn was greater than the mean log doseresponse slope for the remaining 450 "nonreactive" subjects without a significant negative slope (table 3 ).

Table 2 Cross tabulation between non-censored and censored "exponential" $P D_{20}$ values and the presence or absence of a significant negative slope coefficient on linear regression of dose on $F E V$, data

\begin{tabular}{llrl}
\hline$P D_{20}$ & $\begin{array}{l}\text { Slope } \\
\text { present }\end{array}$ & $\begin{array}{l}\text { Slope } \\
\text { absent }\end{array}$ & \\
\hline $\begin{array}{l}\text { Non-censored "exponential" } \\
\text { Censored }(12 \cdot 28 \mu \mathrm{mol})\end{array}$ & 126 & 6 & 132 \\
\cline { 2 - 4 } Total & 227 & 450 & 677 \\
\cline { 2 - 4 } & 353 & 480 & 809 \\
\hline
\end{tabular}




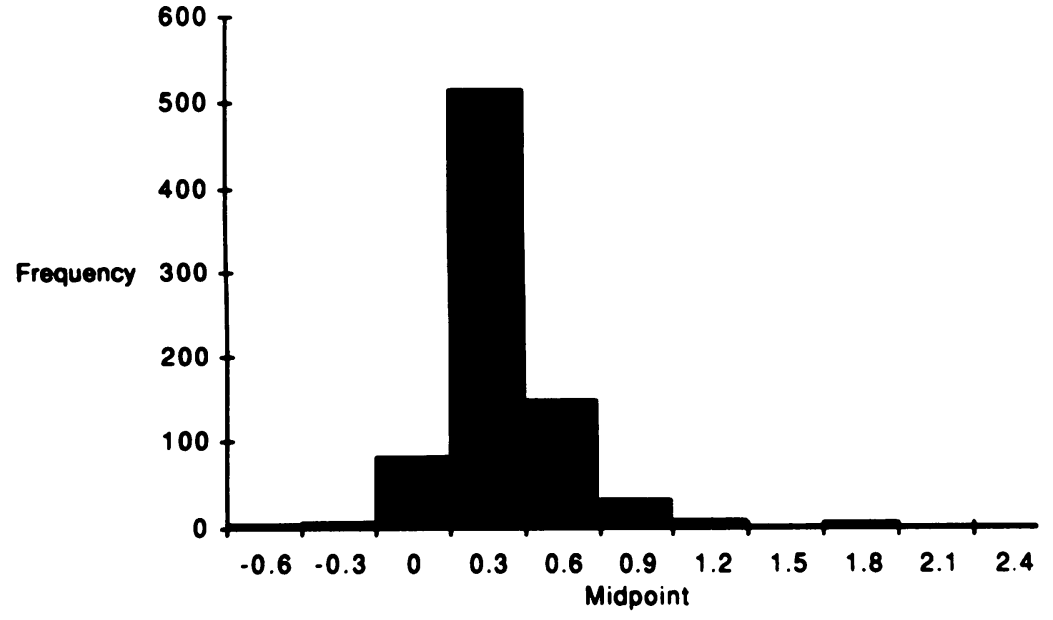

Figure 5 Distribution of log transformed dose-response slope-see figure 1 ( $n=809)$. The quantities are dimensionless.

\section{REPRODUCIBILITY}

The reproducibility or repeatability of bronchial reactivity indices were assessed by measurement of agreement between indices for the same subjects on rechallenge. The intraclass correlation coefficients are listed for interpolated and exponential $\mathrm{PD}_{20}$, inverse cube root of the slope, and log dose-response slope in table 4. The first three indices could be remeasured for only about $60 \%$ of the subjects with non-censored initial values. Adding $1.5 \% / \mu \mathrm{mol}$ before $\log$ transformation failed to eliminate one negative value from the second measurement of dose-response slope. There was a statistically significant agreement between measurements for all indices. The inverse cube root of the slope and log dose-response slope were highly reproducible, exponential $\mathrm{PD}_{20}$ was moderately reproducible, and interpolated $\mathrm{PD}_{20}$ was less reproducible.

\section{CLINICAL VALIDITY}

The clinical validity of the various indices of bronchial reactivity was assessed by comparing subjects who reported features of asthma with

Table 3 Comparison of mean inverse cube root of the slope and log dose-response slope in patients according to their reactivity categories (exponential $P D_{20}<12 \cdot 28 \mu \mathrm{mol}$, significant negative slope on linear regression but censored $P D_{20}$, and non-reactivity according to both indices)

\begin{tabular}{llllll}
\hline & $\begin{array}{l}P D_{20}<12 \cdot 28 \\
\mu m o l \\
(n=132)\end{array}$ & $\begin{array}{l}\text { Negative } \\
\text { slope } \\
(n=227)\end{array}$ & $\begin{array}{l}\text { Non- } \\
\text { reactive } \\
(n=450)\end{array}$ & $\begin{array}{l}\text { Test } \\
\text { used }\end{array}$ & $p$ \\
\hline $\begin{array}{l}\text { Inverse cube root } \\
\text { of the slope }\end{array}$ & 1.89 & 3.14 & - & $\begin{array}{l}t \text { test } \\
(t=20 \cdot 6)\end{array}$ & $<0.0001$ \\
$\begin{array}{l}\text { Log dose-response } \\
\text { slope }\end{array}$ & 0.826 & 0.387 & 0.217 & $\begin{array}{l}\text { Analysis of } \\
\text { variance } \\
(\mathrm{F}=484)\end{array}$ & $<0.0001$ \\
\hline
\end{tabular}

Table 4 Reproducibility of bronchial reactivity indices

\begin{tabular}{|c|c|c|c|}
\hline Index & $n$ & $\begin{array}{l}\text { Intraclass } \\
\text { correlation }\end{array}$ & $p$ \\
\hline $\begin{array}{l}\text { Interpolated } \mathrm{PD}_{20} \\
\text { Exponential } \mathrm{PD}_{20} \\
\text { Inverse cube root of the slope } \\
\text { Log dose-response slope }\end{array}$ & $\begin{array}{r}36 \\
84 \\
206 \\
726\end{array}$ & $\begin{array}{l}0 \cdot 28 \\
0 \cdot 52 \\
0 \cdot 74 \\
0 \cdot 73\end{array}$ & $\begin{array}{l}<0.05 \\
<0.0001 \\
<0.0001 \\
<0.0001\end{array}$ \\
\hline
\end{tabular}

those who did not report such features (table 5). Means values of interpolated $\mathrm{PD}_{20}$ were significantly lower in subjects with a history of asthma and in those who used salbutamol. Mean values of "exponential" $\mathrm{PD}_{20}$ and the inverse cube root of the slope were also significantly lower in subjects who wheezed; mean log dose-response slope was significantly higher in subjects with any of these features. The indices of separation $(\mathrm{D} / \mathrm{s})$ indicated that log dose-response slope best separated asthmatic from non-asthmatic individuals; the inverse cube root of the slope was less efficient, and there was greatest overlap for $\mathrm{PD}_{20}$.

\section{Discussion}

These results support the use of the doseresponse slope ${ }^{11}$ for measuring bronchial reactivity in epidemiological studies. In view of the widespread use and clinical understanding of interpolated $\mathrm{PD}_{20}$ we could argue that this index should also be reported. Interpolated $\mathrm{PD}_{20}$ was of little value in the present study, however, because it applied to only $8 \%$ of subjects. Other attempts to reduce censored data, such as the use of exponential $\mathrm{PD}_{20}$ and the inverse cube root of the slope, do not appear to have a major role.

The apparent improvement in $\mathrm{FEV}_{1}$ with increasing doses of methacholine, seen in $15 \%$ of our subjects, has been reported previously. ${ }^{16}$ It might be an effect of practice or a consequence of slight stiffening of the central airways with agonist administration moving the equal pressure (choke) point downstream. It is also possible that a decline in $\mathrm{FEV}_{1}$ with increasing doses of methacholine could occur from fatigue rather than bronchoconstriction. Subjects had at least two minutes, however, to recover between blows. The reproducibility of bronchial reactivity makes it very unlikely that fatigue is causing a dose related reduction in $\mathrm{FEV}_{1}$.

The usual clinical method of estimating $\mathrm{PD}_{20}$ from interpolation between the last two measurements fails to obtain data from most normal subjects. It provided an index of bronchial reactivity for only $8 \%$ of this occupational sample. The use of a higher dose of agonist might have provided more subjects with an interpolated $\mathrm{PD}_{20}$ as well as information on a plateau response $; 3$ but as subjects had to return to work after being tested we did not think it appropriate to explore maximal responses to methacholine.

The exponential algorithm yields an estimate for $\mathrm{PD}_{20}$ in less than half the number of cases for which simple linear regression yields a significant slope. It has the disadvantage of estimating three parameters from five data points. Extrapolation beyond the dose administered is potentially hazardous for a non-linear function with no estimate of error variance. The results agree well, however, with the conventional interpolated estimate of $\mathrm{PD}_{20}$. The Fortran program operates rapidly and efficiently on a computer.

In summary, the exponential algorithm uses 
Table 5 Comparison of bronchial reactivity indices between subjects with and without features of asthma

\begin{tabular}{|c|c|c|c|c|}
\hline & $\begin{array}{l}\text { History of } \\
\text { asthma }\end{array}$ & $\begin{array}{l}\text { No history } \\
\text { of asthma }\end{array}$ & $D / s$ & $p$ \\
\hline $\begin{array}{l}\text { Mean interpolated } \mathrm{PD}_{20} \\
\text { Mean exponential } \mathrm{PD}_{20} \\
\text { Mean inverse cube root of the slope } \\
\text { Mean log dose-response slope }\end{array}$ & $\begin{array}{l}1 \cdot 76 \\
3 \cdot 84 \\
1.91 \\
0 \cdot 864\end{array}$ & $\begin{array}{l}3 \cdot 18 \\
6 \cdot 08 \\
2 \cdot 79 \\
0 \cdot 335\end{array}$ & $\begin{array}{l}0 \cdot 81 \\
0 \cdot 65 \\
1 \cdot 07 \\
1 \cdot 80\end{array}$ & $\begin{array}{l}<0.005 \\
<0.005 \\
<0.0001 \\
<0.0001\end{array}$ \\
\hline Mean log dose-response slope & Wheeze & No wheeze & $D / s$ & $p$ \\
\hline \multirow[t]{2}{*}{$\begin{array}{l}\text { Mean interpolated } \mathrm{PD}_{20} \\
\text { Mean exponential } \mathrm{PD}_{20} \\
\text { Mean inverse cube root of the slope } \\
\text { Mean log dose-response slope }\end{array}$} & $\begin{array}{l}2 \cdot 40 \\
4 \cdot 10 \\
2 \cdot 26 \\
0 \cdot 556\end{array}$ & $\begin{array}{l}3 \cdot 08 \\
6 \cdot 31 \\
2 \cdot 82 \\
0 \cdot 327\end{array}$ & $\begin{array}{l}0.39 \\
0.64 \\
0 \cdot 67 \\
0 \cdot 78\end{array}$ & $\begin{aligned} & N S \\
< & 0.0005 \\
< & 0.0001 \\
< & 0.0001\end{aligned}$ \\
\hline & $\begin{array}{l}\text { Salbutamol } \\
\text { used }\end{array}$ & $\begin{array}{l}\text { Salbutamol } \\
\text { not used }\end{array}$ & $D / s$ & $p$ \\
\hline $\begin{array}{l}\text { Mean interpolated } \mathrm{PD}_{20} \\
\text { Mean exponential } \mathrm{PD}_{20} \\
\text { Mean inverse cube root of the slope } \\
\text { Mean log dose-response slope }\end{array}$ & $\begin{array}{l}1 \cdot 51 \\
2 \cdot 41 \\
1 \cdot 71 \\
1 \cdot 054\end{array}$ & $\begin{array}{l}2 \cdot 99 \\
5 \cdot 89 \\
2 \cdot 73 \\
0 \cdot 350\end{array}$ & $\begin{array}{l}0 \cdot 85 \\
1 \cdot 02 \\
1 \cdot 24 \\
2 \cdot 39\end{array}$ & $\begin{array}{l}<0.05 \\
<0.001 \\
<0.0001 \\
<0.0005\end{array}$ \\
\hline
\end{tabular}

$\star$ Differences in means were assessed by the $t$ test and the index of separation $(\mathrm{D} / \mathrm{s})$ was calculated as difference in means/pooled standard deviation. ${ }^{22}$

all data and does not assume linearity. It provided an estimate of $\mathrm{PD}_{20}$ in a greater proportion of this occupational sample than interpolation, was reproducible and valid, and has been used in other population studies. ${ }^{124}$ In studies including many asthmatic subjects the results have often been expressed as $\log \mathrm{PD}_{20}$. As log transformation did not normalise the distribution of the exponential estimate of $\mathrm{PD}_{20}$ in our occupational population the original scale in $\mu \mathrm{mol}$ was retained for analysis. In any case a normal distribution might not be expected in the "hyperreactive" tail of bronchial reactivity measurements. A censored index such as $\mathrm{PD}_{20}$, which can be derived for only a small proportion of the general population, represents only this tail of the distribution.

The transformed slope coefficient is a continuous index of bronchial reactivity applicable to a larger proportion of the population than $\mathrm{PD}_{20}$. The inverse cube root of the slope was estimated for $44 \%$ of subjects in this aluminium smelter who showed a significant linear dose-response relationship. There are some concerns about its use. Slopes from regression lines that did not significantly differ from zero were excluded, so that $56 \%$ of subjects had censored values. Very small slopes became large outlying values after reciprocal transformation. Although these outlying values could be reduced by the addition of an increment (similar to the one added to the dose-response slope before log transformation), none of our conclusions was altered by including slopes from non-significant regression lines. We thought that this effort added little useful information to the dose-response slope, which was much simpler to calculate.

Another theoretical problem was the undue influence of outlying points on each regression line. In a minimally reactive subject the highest dose given $(6 \cdot 14 \mu \mathrm{mol})$ was four times the previous dose $(1.54 \mu \mathrm{mol})$. Statistical testing did not, however, identify excessive influence on the line of best fit from this outlying point.
In any case, such influence could be considered biologically appropriate as most of the response occurred at higher doses.

The inverse cube root of the slope had the desirable biological and statistical property of being normally distributed, was reproducible, and had clinical validity. The inverse cube root scale is unusual, but not entirely without parallel in respiratory epidemiology. For instance, the latent period for the development of respiratory cancer appears to be related to the inverse cube root of asbestos dose. ${ }^{25}$ The inverse cube root of the slope is interpreted in the same manner as $\mathrm{PD}_{20}$ in that the larger the value the less reactive the subject. There was excellent agreement between $\mathrm{PD}_{20}$ and the cube root of the slope measurements, and subjects lacking an estimate of $\mathrm{PD}_{20}$ had significantly greater values for the inverse cube root of the slope. Subjects with slope alone have measurable reactivity, but of a lesser degree than those with both slope and $\mathrm{PD}_{20}$. This was confirmed by the differences in mean log dose-response slope.

The most widely applicable index of bronchial reactivity is the dose-response slope, which could be calculated for all subjects. The single parameter is simple to calculate and agrees well with the slope from linear regression, as has been previously found. ${ }^{11}$ This model does, however, assume that the first and last measurements of $\mathrm{FEV}_{1}$ were made without error, which is unlikely, and the absence of any test of statistical significance means that all subjects contribute a dose-response slope and this will include random noise. Subjects showing an increase in $\mathrm{FEV}_{1}$ from its post-saline baseline to the final dose of methacholine are certainly less reactive than those who show a decrease, but they may differ little from those whose $\mathrm{FEV}_{1}$ shows little or not change. Thus assignment of a number to their lack of reactivity is hard to justify. Despite the incorporation of data from such subjects log doseresponse slope was highly reproducible.

Although the distribution of log dose-response slope was not normal, log transformation allowed bronchial reactivity to be expressed on a familiar logarithmic scale. The increment for eliminating negative and zero values before log transformation requires standardisation. The previously suggested $0 \cdot 3 \% / \mu \mathrm{mol}^{11}$ would have been insufficient in the present study. Alternatively, untransformed dose-response slope values could be analysed by non-parametric statistical tests, which are sufficiently robust not to be unduly influenced by the severely skewed distribution.

In conclusion, measuring the dose-response slope has the advantages of simplicity, reproducibility, clinical validity, and absence of censored data. Neither exponential $\mathrm{PD}_{20}$ nor the inverse cube root of the slope combines these desirable features in a single index. We would recommend using the dose-response slope for analysis of bronchial reactivity in future epidemiological studies.

The study was sponsored by a grant to the University of Newcastle from Alcan Australia Limited. MJA was a postgraduate medical research scholar of the National Health and 
Medical Research Council. We wish to thank Paula Watts for assistance in testing subjects and John Wlodarczyk for project and data management. Susan Chinn kindly provided the Fortran program to estimate $\mathrm{PD}_{20}$ and Ira Tager made helpful comments on the analysis of the data. Stephen Farish provided statistical advice.

1 Britton WJ, Woolcock AJ, Peat JK, Sedgwick CJ, Lloyd DM, Leeder SR. Prevalence of bronchial hyperresponsiveness in children: the relationship between asthma and skin reactivity to allergens in two communities. Int $J$ Epidemiol 1986;15:202-9.

2 Salome CM, Peat JK, Britton WJ, Woolcock AJ. Bronchial hyper-responsiveness in two populations of Australian school children. I. Relation to respiratory symptoms and diagnosed asthma. Clin Allergy 1987;17:271-81.

3 Woolcock AJ, Peat JK, Salome CM, et al. The prevalence of bronchial hyperresponsiveness and asthma in a rural adult population. Thorax 1987;42:361-8.

4 Asher MI, Pattemore PK, Harrison AC, Mitchell EA, Rea HH, Stewart AW, Woolcock AJ. International comparisons of the prevalence of asthma symptoms and bronchial hyper-responsiveness. Am Rev Respir Dis 1988;138:524-9.

5 Sears MR, Jones DT, Holdaway MD, Hewitt CJ, Flannery EM, Herbison GP, Silva PA. Prevalence of bronchial reactivity to inhaled methacholine in New Zealand children. Thorax 1986;41:283-9.

6 Dowse GK, Smith D, Turner KJ, Alpers MP. Prevalence and features of asthma in a sample survey of urban Goroka, Papua New Guinea. Clin Allergy 1985;15: 429-38.

7 Burney PGJ, Britton JR, Chinn S, Tattersfield AE, Papacosta AO, Kelson MC, Anderson F, Corfield DR. Descriptive epidemiology of bronchial reactivity in an adult population: results from a community study. Thorax 1987;42:38-44.

8 Mortagy AK, Howell JB, Waters WE. Respiratory symptoms and bronchial reactivity: identification of a syndrome and its relation to asthma. Br Med J 1986;293:525-9.

9 Cockcroft DW, Berscheid BA. Slope of the dose-response curve: usefulness in assessing bronchial response to inhaled histamine. Thorax 1983;38:55-61.

10 Malo J-L, Cartier A, Pineau L, Gagnon G, Martin R. Slope of the dose-response curve to inhaled histamine and methacholine and $\mathrm{PC}_{20}$ in subjects with symptoms of airway hyperexcitability and in normal subjects. Am Rev Respir Dis 1985a;132:644-7.

11 O'Connor G, Sparrow D, Taylor D, Segar, M, Weiss ST. Analysis of dose-response curves to methacholine: an approach suitable for population studies. Am Rev Respir Dis 1987;136:1412-7.

12 Bellia V, Rizzo A, Amoroso S, Mirabella A, Bonsignore G. Analysis of dose response curves in the detection of bronchial hyperreactivity. Respiration 1983;44:10-8.

13 Yan K, Salome C, Woolcock AJ. Rapid method for measurement of bronchial responsiveness. Thorax 1983;38:760-5.

14 Gardner RM, Hankinson JL, Clausen JL, Crapo RO, Johnson RL, Epler GR. Standardisation of spirometry1987 update. Am Rev Respir Dis 1987;136:1285-98.

15 Chai H, Farr RS, Froelich LA, et al. Standardisation of bronchial inhalation challenge procedures. J Allergy Clin Immunol 1975;56:323-7.

16 Chinn S, Britton JR, Burney PGJ, Tattersfield AE, Papacosta AO. Estimation and repeatability of the response to inhaled histamine in a community study. Thorax 1987;42:45-52.

17 Ryan TA, Joiner BL, Ryan BF. Minitab reference manual. Boston: Duxbury Press, 1981.

18 Colton T. Statistics in medicine. Boston: Little, Brown and Company, 1974.

19 Landis JR, Koch GG. A review of statistical methods in the analysis of data arising from observer reliability studies. Statistica Neederlandica 1975;29:101-23.

20 Fletcher CM, Peto R, Tinker C, Speizer F. The natural history of chronic bronchitis and emphysema. Oxford: Oxford University Press, 1976.

21 Huntsberger DV, Billingsley P. Elements of statistical inference. 5th ed. Boston: Allyn and Bacon, 1981:379-81.

22 Armitage $P$, Berry G. Statistical methods in medical research. 2nd ed. Oxford: Blackwell, 1987:474-5.

23 Woolcock AJ, Salome CM, Yan K. The shape of the dose response curve to histamine in asthmatic and normal subjects. Am Rev Respir Dis 1984;130:71-5.

24 Britton JR, Burney PGJ, Chinn S, Papacosta AO, Tattersfield AE. The relationship between change in airway reactivity and change in respiratory symptoms and medication in a community study. Am Rev Respir Dis medication in a

25 Enterline PE. Estimating health risks in studies of the health effects of asbestos. Am Rev Respir Dis 1976;113:175-80. 